UNIVERSITE DE LAUSANNE - FACULTE DE BIOLOGIE ET DE MEDECINE DEPARTEMENT DE RADIOLOGIE MEDICALE SERVICE DE RADIO-ONCOLOGIE

Chef de Service : Professeur René-Olivier Mirimanoff

PRIMARY SPINAL EPIDURAL LYMPHOMA :

PATIENTS' PROFILE, OUTCOME, AND PROGNOSTIC FACTORS:

A MULTICENTER RARE CANCER NETWORK STUDY.

THESE

Présentée à la Faculté de Biologie et de Médecine de l'Université de Lausanne Pour l'obtention du grade de

DOCTEUR EN MEDECINE

WH

525

Mon

\author{
par \\ Virginie Monnard \\ Médecin diplômée de la Confédération Suisse \\ Originaire d'Attalens
}




\section{LYMPHOMES EPIDURAUX PRIMAIRES: RESULTATS ET FACTEURS PRONOSTICS : UNE ETUDE DU «RARE CANCER NETWORK».}

\section{RESUME :}

Objectif: Les lymphomes épiduraux primaires représentent moins de $10 \%$ des tumeurs épidurales et de 0,1 à $3,3 \%$ de tous les lymphomes. Le but de cette étude a été d'évaluer le profil clinique de cette maladie rare, son traitement, ses résultats ainsi que ses facteurs de pronostic.

Matériel et méthode : Entre 1982 et 2002, 52 patients présentant un lymphome épidural primaire ont été traités dans neuf institutions membres du Rare Cancer Network. Les critères d'inclusion comprenaient : une biopsie confirmant le lymphome non-hodgkinien, un stade IE et IIE selon la classification de Ann Arbor, un traitement à visée curative de radiothérapie combinée ou non à une chimiothérapie et un suivi d'au moins six mois. Selon la Working Formulation, 12 patients $(23 \%)$ présentaient un lymphome de bas grade, $28(54 \%)$ un grade intermédiaire et $12(23 \%)$ un haut grade. Les hommes étaient atteints 1.9 fois plus fréquemment que les femmes. L'âge moyen était de 61 ans (intervalle : 21 à 96). Le bilan incluait un Ct-scan spinal (98\%), une IRM (52\%), un CT-scan thoraco-abdominal (77\%) et une aspiration ou biopsie de moelle osseuse (96\%). Les symptômes les plus fréquents comprenaient des douleurs dorsales (79\% des patients), une faiblesse musculaire (92\%) et des déficits sensoriels (71\%). Quarante-huit patients ont subi une laminectomie de décompression avec résection partielle ou complète ( $42 \%$ et $13 \%$ des cas respectivement), tous ont reçu une radiothérapie seule (20 patients) ou en combinaison avec une chimiothérapie (32 patients). La dose médiane totale était de $36 \mathrm{~Gy}$ (intervalle 6-50 Gy) avec une moyenne de 20 Gy par fraction (intervalle : 1-25). Le suivi moyen était de 71 mois (intervalle : 22-165 mois).

Résultats : Suite au traitement, une progression locale a été observée chez 6 patients après un temps de latence moyen de 6 mois. Le taux de rechute systémique a été de $42 \%$ ( 22 patients) le plus souvent dans les ganglions lymphatiques $(n=9)$ après un intervalle de temps moyen de 20 mois. Lors du dernier contrôle, 28 patients étaient vivants et 24 patients étaient décédés. Le taux de survie à 5 ans, le taux de survie sans maladie et le contrôle local étaient de $69 \%$, $57 \%$ et $88 \%$ respectivement. En analyse univariée, les facteurs pronostics favorables statistiquement significatifs concernant la survie sans maladie étaient un âge inférieur à 63 ans, ainsi qu'une réponse neurologique complète. Pour la survie à 5 ans, les facteurs favorables étaient un âge inférieur à 63 ans. En analyse multivariée, les facteurs pronostics favorables pour la survie globale à 5 ans étaient une réponse neurologique complète, un traitement combiné, un volume de radiothérapie plus que focal, une dose totale de radiothérapie supérieure à 36 Gy et une résection partielle ou complète de la tumeur. En ce qui concerne la survie sans maladie, les facteurs pronostics favorables étaient un âge inférieur à 63 ans et un traitement combiné.

Conclusion : Ce qui ressort de cette analyse est que le bilan diagnostic devrait inclure une IRM ou un CT-scan, un échantillon de tissu pour poser le diagnostic pathologique définitif de la lésion, une histoire médicale et un examen physique complet, une chimie sanguine, un CTscan thoraco-abdominal et une biopsie de la moelle osseuse, un PET-scan devrait également faire partie du bilan. Le traitement devrait consister, dans la phase aiguë, en une chirurgie de décompression avec ou sans résection, suivie d'une radiothérapie d'au moins 36Gy en 2 Gy par fraction et d'une chimiothérapie. Tous les patients présentant un lymphome de haut grade ou de grade intermédiaire devraient pouvoir bénéficier d'un traitement combiné. 


\title{
PRIMARY SPINAL EPIDURAL LYMPHOMA: PATIENTS' PROFILE, OUTCOME, AND PROGNOSTIC FACTORS: A MULTICENTER RARE CANCER NETWORK STUDY
}

\author{
Virginie Monnard, M.S.,* Alex Sun, M.D., ${ }^{\dagger}$ Ron Epelbaum, M.D., ${ }^{*}$ Philip Poortmans, M.D., \\ Robert C. Miller, M.D.," Tom Verschueren, M.D.,"l Luciano Scandolaro, M.D.," \\ Salvador Villa, M.D., ${ }^{* *}$ Sabine Balmer Majno, M.D. ${ }^{\dagger \dagger}$ Sandrine Ostermann, M.D., Ph.D.,** \\ Mahmut Ozsahin, M.D., Ph.D.,* and René-Olivier Mirimanoff, M.D.* \\ *Department of Radiation Oncology, Centre Hospitalier Universitaire Vaudois, Lausanne, Switzerland; "Department of Radiation \\ Oncology, The Princess Margaret Hospital, Toronto, Ontario, Canada; ${ }^{\ddagger}$ Department of Oncology, Rambam Medical Centre, Haifa, \\ Israel; "Department of Radiotherapy, Dr. Bernard Verbeeten Instituut, Tilburg, The Netherlands; "Division of Radiation Oncology, \\ Mayo Clinic. Rochester, MN; "Department of Radiation Oncology MAASTRO, University Hospital, Maastricht, The Netherlands; \\ "Department of Radiation Oncology, Ospedale Sant'Anna, Como, Italy; ** Department of Radiation Oncology, \\ Institut Català d'Oncologia. Barcelona, Spain; ${ }^{\dagger \dagger}$ Hôpital Cantonal Universitaire de Genève (HCUGE), Geneva, Switzerland
}

\begin{abstract}
Purpose: To assess the clinical profile, treatment outcome, and prognostic factors in primary spinal epidural Iymphoma (PSEL).

Methods and Materials: Between 1982 and 2002, 52 consecutive patients with PSEL were treated in nine institutions of the Rare Cancer Network. Forty-eight patients had an Ann Arbor stage IE and four had a stage IIE. Forty-eight patients underwent decompressive laminectomy, all received radiotherapy $\left(\mathrm{R}^{\prime} \mathrm{T}\right)$ with $(n=32)$ or without chemotherapy $(n=20)$. Median RT dose was $36 \mathrm{~Gy}$ (range, 6-50 Gy).

Results: Six $(11 \%)$ patients progressed locally and $22(42 \%)$ had a systemic relapse. At last follow-up, 28 patients were alive and 24 had died. The 5-year overall survival, disease-free survival, and local control were $69 \%, 57 \%$, and $88 \%$, respectively, In univariate analyses, favorable prognostic factors were younger age and complete neurologic response. Multivariate analysis showed that combined modality treatment, RT volume, total dose more than $36 \mathrm{~Gy}$, tumor resection, and complete neurologic response were favorable prognostic factors.

Conclusions: Primary spinal epidural lymphoma has distinct clinical features and outcome, with a relatively good prognosis, After therapy, local control is excellent and systemic relapse occurs in less than half the cases. Combined modality treatment appears to be superior to RT alone. (C) 2006 Elsevier Inc.
\end{abstract}

Primary spinal epidural lymphoma, Non-Hodgkin's lymphoma, Spinal cord compression, Radiation therapy, Chemotherapy, Combined modality treatment.

\section{INTRODUCTION}

The term "primary spinal epidural lymphoma" (PSEL) is used to define lymphomas primarily occurring in the epidural space in the absence of other previously detected lymphomatous foci.

Epidural localization is a rare presenting site in nonHodgkin's lymphomas (NHL), and accounts for $10 \%$ of epidural spinal tumors (1) and for 0.1 to $3.3 \%$ of all lymphomas $(2,3)$. Because of the rarity of this entity, we found in the literature only retrospective studies including a relatively small number of patients from one institution, or single case reports. So far, the largest series has identified
49 patients over 62 years (1907-1969) and was reported by Haddad et al. from the Mayo Clinic (4). Apart from this unique and relatively large series, most articles have reported small number of patients: Levitt et al. studied 9 cases of epidural presentation among 592 patients with NHL (5), Epelbaum et al. 10 patients of 453 (6), Goffinet $e t$ al. 7 of 423 (7), and Rudders et al. 2 of 380 (8). Because of the limited number of patients and the large timespan, the parameters of this disease, such as natural history, prognostic factors, treatment techniques, and survival have been difficult to establish. For this reason, and to collect a larger number of patients suffering from this type of rare entity, we
Reprint requests to: René-Olivier Mirimanoff, M.D., Department of Radiation Oncology, Centre Hospitalier Universitaire Vaudois (CHUV), Rue du Bugnon 46, CH-1011 Lausanne, Switzerland. Fax: (+41) 21-314-4664; E-mail: rene-olivier.mirimanoff@chuv.ch

Presented in part at the 45th Annual Meeting of the American Society for Therapeutic Radiology and Oncology (ASTRO), Salt
Lake City, UT, October 19-23, 2003.

Acknowledgments-The authors are grateful to Frances Godson for her help in the preparation of the manuscript.

Received Oct 27, 2005, and in revised form Jan 5, 2006. Accepted for publication Jan 7, 2006. 
have established a collaborative, multi-institutional group to study rare forms of cancers, the Rare Cancer Network (www.rarecancer.net). Thus the purpose of this study was to better assess the clinical profile, treatment outcome, and prognostic factors in patients strictly staged as IE or IIE primary spinal epidural lymphoma. We excluded secondary epidural involvement from more advanced NHL from this study.

\section{METHODS AND MATERIALS}

\section{Patients characteristics}

Sixty-two cases of primary spinal epidural lymphoma were evaluated and treated in nine member institutions of the Rare Cancer Network between 1982 and 2002. Only 52 patients with biopsy-proven NHL, with a stage IE or IIE disease according to the Ann-Arbor classification (9), with a curative-intent treatment by radiotherapy (RT) with or without chemotherapy, and with a minimal follow-up of 6 months were included in this study. Thus 10 patients, 4 with suspicion of infiltration of the bone marrow (Stage IV) and 6 with an insufficient follow-up, 3 of whom staged as IV, had to be excluded.

All lymphomas in this series were classified according to the Working Formulation (10), because it was thought to be the most reproducible classification when reclassifying cases included in a 20-year period, and coming from nine different institutions. Thus 12 patients $(23 \%)$ had a low-grade, $28(54 \%)$ intermediate-grade, and $12(23 \%)$ high-grade NHL. Only those patients who were strictly staged as IE $(n=48)$ or IIE $(n=4)$ were selected for the study.

The 52 patients included 36 men (69\%) and 16 women $(31 \%)$, with a male-to-female ratio of 2.25 . The median age was 61 years (range, 21-96 years). The median follow-up was 71 months (range, 22-165 months).

For all patients, a medical history was taken and physical examination was carried out. Staging work-up included a spinal computed tomography (CT) scan (98\% of patients) and/or magnetic resonance imaging (MRI) $(52 \%)$, whole-body $\mathrm{CT}$ scan $(77 \%)$, myelogram $(65 \%)$, and bone marrow aspiration or biopsy (96\%). Thirty-six patients had a cerebrospinal fluid examination,

Table 1. Staging workup in 52 patients with primary spinal epidural lymphoma

\begin{tabular}{lll}
\hline \multicolumn{1}{c}{ Staging workup } & $n$ & $\%$ \\
\hline Myelogram & 34 & 65 \\
Whole-body CT scan & 40 & 77 \\
MRI & 27 & 52 \\
Spinal CT scan & 51 & 98 \\
Cerebrospinal fluid exam & 26 & 50 \\
Bone marrow aspiration or biopsy & 50 & 96 \\
Gallium scan & 14 & 27 \\
LDH & 44 & 84 \\
WBC & 49 & 94 \\
B2 microglobulin & 11 & 21 \\
ESR & 21 & 40 \\
Serum protein electrophoresis & 23 & 44 \\
\hline
\end{tabular}

Abbreviations: $\mathrm{CT}=$ computed tomography; $\mathrm{MRI}=$ magnetic resonance imaging; $\mathrm{LDH}=$ lactate dehydrogenase; $\mathrm{WBC}=$ white blood cell count; ESR = erythrocyte sedimentation rate.
Table 2. Patients' characteristics

\begin{tabular}{lrr}
\hline \multicolumn{1}{c}{ Characteristics } & $n$ & $\%$ \\
\hline Gender & & \\
Male & 36 & 69 \\
Female & 16 & 31 \\
Symptoms and signs & 41 & 79 \\
Back pain & 6 & 11 \\
Neck pain & 46 & 88 \\
Lower limb weakness & 5 & 9 \\
Upper limb weakness & 37 & 71 \\
Sensory deficit & 10 & 19 \\
Sphincter dysfunction & 9 & 17 \\
Bowel dysfunction & 12 & 23 \\
Bladder dysfunction & & \\
Localization & 34 & 65 \\
Thoracic & 6 & 11 \\
Lumbar & 5 & 10 \\
Cervical & 2 & 4 \\
Lumbo-sacral & 2 & 4 \\
Cervico-thoracic & 3 & 6 \\
Thoraco-lumbar & & \\
Stage & 48 & 23 \\
IE & 4 & 54 \\
IIE & 12 & 23 \\
Grade & 28 & \\
Low & 12 & \\
Intermediate & & \\
High & & \\
\hline
\end{tabular}

none of which was positive for the presence of abnormal cells. Staging workup for all patients is shown in detail in Table 1.

The thoracic region was the most common disease site in 34 patients $(65 \%)$. Other sites were lumbar region in 6 patients $(11 \%)$, cervical in $5(10 \%)$, thoraco-lumbar in $3(6 \%)$, lumbo-sacral in 2 (4\%), and cervico-thoracic segment in $2(4 \%)$. Regarding the 4 patients with stage IIE, the thoracic region was involved in 2 patients, the lumbar and the lumbo-sacral regions each in 1 patient,

The most common symptoms were motor weakness (92\%), back pain (79\%), sensory deficits $(71 \%)$, sphincter dysfunction (19\%), bladder dysfunction (23\%), and bowel dysfunction (17\%). Two patients had unexplained weight loss and one presented with night sweats; otherwise, none of the remaining patients presented with "B" symptoms and none had hepatomegaly or splenomegaly. The time from the first symptom to the diagnosis varied from 1 day to 1 year. The patients' characteristics are presented in Table 2 .

\section{Treatment}

Forty-eight patients $(92 \%)$ underwent a decompressive laminectomy, and partial or complete resection was performed in 22 cases $(42 \%)$ and in 7 cases $(13 \%)$, respectively. All patients received RT, either alone $(n=20)$ or combined with chemotherapy $(n=32)$. Fourteen patients underwent RT before chemotherapy, 16 underwent chemotherapy before RT, one had a "sandwich" modality, and 1 had a concomitant treatment.

\section{Radiotherapy}

The median RT dose was 36 Gy (range, 6-50 Gy) in a median 20 fractions (range, 1-25 fractions). Ten patients had a focal treatment (i.e., a treatment focused only on the vertebral segment with the lymphomatous lesion), whereas the remaining 42 received more than focal treatment: 1 patient was treated on 17 vertebral 
bodies, 1 on 13,2 on 12,4 on 10,3 on 8,8 on 7,9 on 6,11 on 5 , 2 on 4 , and 1 patient on 3 vertebral bodies. In 31 cases, the RT technique included one posterior ficld, the remainder having two or more converging beams.

\section{Chemotherapy}

Thirty-two of the 52 patients (61\%) had chemotherapy. For 18 of them, chemotherapy consisted of cyclophosphamide, doxorubicin, vincristine, and prednisone, with 11 receiving six cycles, 1 receiving five cycles, 3 receiving four cycles, 2 receiving threc cycles, and 1 receiving one cycle. Two patients received cyclophosphamide, epirubicin, vincristine, and prednisone, 1 for six cycles and 1 for three cycles. Four patients received a combination of bleomycin, Adriamycin, cyclophosphamide, vincristine, and prednisone, with 2 receiving three cycles, and 2 receiving one cycle. Two patients had methotrexate, doxorubicin, cyclophosphamide, vincristine, prednisone, and bleomycin in three cycles. One received cyclophosphamide, vincristine, and prednisone in six cycles. Three patients received a combination of prednisone, doxorubicin, cyclophosphamide, etoposide, cytarabine, bleomycin, vincristine, methotrexate, and leucovorin, 1 in eight cycles and 2 in six cycles. One patient received epirubicin, vincristine, etoposide, cyclophosphamicle, and prednisone for six cycles. In I patient, the type of chemotherapy could not be found. Intrathecal methotrexate was administered in 10 patients.

\section{Chemotherapy according to age, grade, and stage}

Of the 25 patients older than 63 years, $13(52 \%)$ received chemotherapy versus 19 of $27(70 \%)$ of patients younger than 63 years. With regard to grade, 3 of $12(25 \%)$ with low grade, 19 of $28(68 \%)$ with intermediate grade, and 10 of $12(83 \%)$ with high grade had chemotherapy. All 4 patients with stage IIE were treated with chemotherapy versus 28 of $48(58 \%)$ with stage IE,

\section{Statistical analysis}

Disease-free survival (DFS), overall survival (OS), and local control were calculated from the date of biopsy using the KaplanMeier method (11). The events were death (including all causes of death) for OS, death (including all causes of death) or relapse for DFS, and local relapse for local control. Differences between groups were assessed using the log-rank test (12). We screened for independent prognostic factors with a Cox regression analysis (13). A $p$ value of $<0.05$ was considered statistically significant.

Neurologic response was defined as (1) complete neurologic response (i.e., complete recovery of any motor deficit from PSEL); (2) partial neurologic response when there was incomplete motor recovery; or (3) no response if there was no motor recovery after treatment.

\section{RESULTS}

\section{Response rate, local control, and systemic relapse}

Of the 48 patients who presented initially with motor weakness, $12(25 \%)$ had a complete neurologic response and $36(75 \%)$ had a partial neurologic response. Local progression was observed in 6 patients at 5.2, 5.5, 5.7, 6, 43, and 92 months, respectively, after the initial diagnosis. The median time to local relapse was 6 months with a local control rate of $88 \%$.

Systemic relapses were observed in 22 patients (42\%) after a median latency period of 20 months. Those were mainly in lymph nodes $(n=9)$, chest or abdomen $(n=5)$, bone marrow $(n=4)$, and the central nervous system (CNS) $(n=$ $4)$. The characteristics of patients with CNS relapse, their second treatment, and outcome are presented in Table 3.

\section{Survival}

The 5-year OS, DFS, and local control were $69 \%, 57 \%$, and $88 \%$ respectively (Fig. 1). Eighteen patients died from their lymphoma and 6 from other causes ( 2 from esophageal cancer, 1 from colon cancer, 1 from cerebral hemorrhage, 1 from a ruptured aneurysm, and 1 from sepsis).

\section{Prognostic factors}

Univariate analyses revealed that younger age $\quad<63$ years) and complete neurologic response were statistically significant favorable prognostic factors for DFS, whereas

Table 3. Characteristics of patients with CNS relapse

\begin{tabular}{|c|c|c|c|c|}
\hline & Patient 1 & Patient 2 & Patient 3 & Patient 4 \\
\hline Sex & $\mathrm{M}$ & $\mathrm{M}$ & $\mathrm{F}$ & $\mathrm{M}$ \\
\hline Age & 69 & 66 & 56 & 67 \\
\hline Grade & Intermediate & High & Intermediate & Intermediate \\
\hline Stage & IEA & IEA & IEA & IEA \\
\hline Initial localization & Thoracic spine & Thoracic spine & Thoracic spine & Thoracic-lumbar spine \\
\hline Initial treatment & $\mathrm{RT}+\mathrm{BACOP}$ & RT alone & $\begin{array}{l}\text { RT + ProMACE/ } \\
\text { CytaBOM }\end{array}$ & RT alone \\
\hline "Prophylactic" IT MTX & None & None & None & None \\
\hline Localization at recurrence & Subarachnoid spread & Suparachnoid spread & Subarachnoid spread & $\begin{array}{l}\text { Subarachnoid spread and } \\
\text { cranial nerve involvement }\end{array}$ \\
\hline Treatment at recurrence & $\begin{array}{l}\text { Ara-C, etoposide, } \\
\text { IT MTX }\end{array}$ & $\begin{array}{l}\text { Patient refused } \\
\text { treatment }\end{array}$ & CHOP & $\begin{array}{l}\text { Cranial RT, IT MTX, } \\
\text { chemotherapy (unspecified) }\end{array}$ \\
\hline Outcome & $\mathrm{D}+\mathrm{D}$ & $\mathrm{D}+\mathrm{D}$ & $D+D$ & $D+D$ \\
\hline
\end{tabular}

Abbreviations: $\mathrm{M}=$ male; $\mathrm{F}=$ female; $\mathrm{CSF}=$ cerebrospinal fluid; $\mathrm{IT} \mathrm{MTX}=$ intrathecal methotrexate; $\mathrm{D}+\mathrm{D}=$ dead with disease; $\mathrm{BACOP}=$ bleomycin, adriamycin, cyclophosphamide, vincristine, and prednisone; $\mathrm{CNS}=$ central nervous system; $\mathrm{RT}=$ radiotherapy; $\mathrm{CHOP}=$ cyclophosphamide, doxorubicin, prednisone, vincristine; ProMACE/CytaBOM = bleomycin, cyclophosphamide, cytarabine, doxorubicin, etoposide, leucovorin, methotrexate, prednisone, vincristine; Ara-C $=$ cytarabine. 


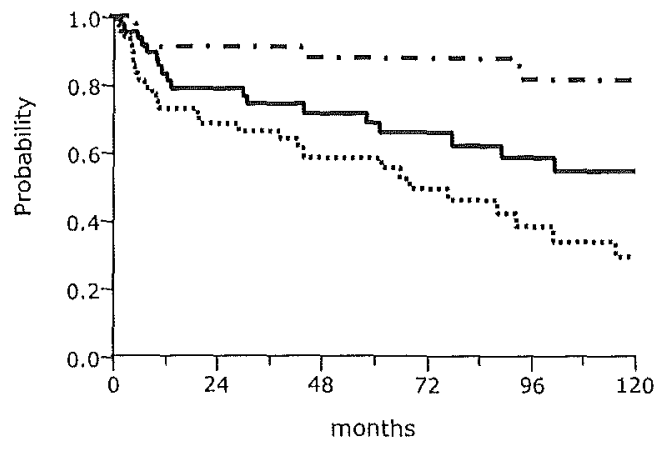

Patients at risk
OS

........ DFS

Local control

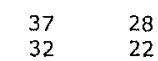

28
22
25

22
17

17

16

$13 \quad 10$
Fig. 1. Overall survival (OS), disease-free survival (DFS), and local control in 52 patients with primary spinal epidural lymphoma.

combined modality treatment conferred an advantage of borderline insignificance. For OS, only age proved to be significant (Table 4).

In multivariate analysis, the favorable independent prognostic factors influencing OS were complete neurologic response, combined modality treatment, RT volume more than focal, total RT dose more than $36 \mathrm{~Gy}$, and complete or

Table 4. Univariate analysis (log-rank test)

\begin{tabular}{|c|c|c|c|c|c|}
\hline & $n$ & $\begin{array}{c}\text { 5-year } \\
\text { OS }(\%)\end{array}$ & $\begin{array}{c}p \\
\text { value }\end{array}$ & $\begin{array}{c}\text { 5-year } \\
\text { DFS (\%) }\end{array}$ & $\begin{array}{c}p \\
\text { value }\end{array}$ \\
\hline All patients & 52 & 69 & & 57 & \\
\hline \multicolumn{6}{|l|}{ Age (years) } \\
\hline$<63$ & 27 & 88 & 0.001 & 76 & 0.001 \\
\hline$>63$ & 25 & 50 & & 33 & \\
\hline \multicolumn{6}{|l|}{$\operatorname{Sex}$} \\
\hline $\mathrm{M}$ & 36 & 69 & NS & 57 & NS \\
\hline $\mathrm{F}$ & 16 & 61 & & 50 & \\
\hline \multicolumn{6}{|l|}{ Stage } \\
\hline $\mathrm{IE}$ & 48 & 66 & NS & 58 & NS \\
\hline IIE & 4 & 100 & & 25 & \\
\hline \multicolumn{6}{|l|}{ Grade } \\
\hline Low & 16 & 65 & NS & 50 & NS \\
\hline Intermediate/high & 36 & 70 & & 53 & \\
\hline \multicolumn{6}{|l|}{ LDH } \\
\hline Abnormal & 11 & 90 & NS & 38 & NS \\
\hline Normal/not done & 41 & 86 & & 55 & \\
\hline \multicolumn{6}{|l|}{ Treatment } \\
\hline RT alone & 20 & 60 & NS & 40 & 0.07 \\
\hline $\begin{array}{l}\text { Combined } \\
\text { treatment }\end{array}$ & 32 & 75 & & 61 & \\
\hline \multicolumn{6}{|l|}{ RT volume } \\
\hline Focal & 10 & 100 & NS & 38 & NS \\
\hline More than focal & 42 & 84 & & 55 & \\
\hline \multicolumn{6}{|l|}{ Neurologic response } \\
\hline CR & 13 & 85 & 0.09 & 78 & 0.02 \\
\hline PR & 35 & 62 & & 4.5 & \\
\hline
\end{tabular}

Abbreviations: $\mathrm{OS}=$ overall survival; $\mathrm{DFS}=$ disease-free survival; NS $=$ not significant; $\mathrm{CR}=$ complete neurologic response; $\mathrm{PR}=$ partial neurologic response; $\mathrm{M}=$ male; $\mathrm{F}=$ female; $\mathrm{RT}=$ radiotherapy; $\mathrm{LDH}=$ lactic dehydrogenase.
Table 5. Multivariate analysis (Cox model)

\begin{tabular}{lcc}
\hline \multicolumn{1}{c}{ Factor } & OS ( $p$ value $)$ & DFS $(p$ value $)$ \\
\hline Combined treatment & 0.005 & 0.02 \\
Neurologic response & 0.001 & NS \\
Age <63 years & NS & 0.006 \\
RT volume more than focal & 0.001 & NS \\
RT dose more than 36 Gy & 0.01 & NS \\
Resection of the tumor mass & 0.004 & NS \\
\hline
\end{tabular}

Abbreviations: $O S=$ overall survival; $D F S=$ disease-free survival; NS $=$ not significant; $\mathrm{RT}=$ radiotherapy.

partial lymphoma resection; those influencing DFS were age younger than 63 years of age and combined modality treatment (Table 5).

It is quite likely that neurologic response reflected tumor response. Unfortunately, because of the retrospective nature of this analysis, a reliable assessment of the tumor response could not be obtained in most patients, in contrast to the neurologic status and response, which were well recorded.

\section{Acute side effects}

Four patients ( $8 \%$ ) presented with Grade 1 skin reactions; $3(6 \%)$ had Grade 2 and $1(2 \%)$ Grade 3 oropharyngeal mucositis, whereas 4 patients had Grade 2 esophagitis. Two patients complained of fatigue, 4 of nausea and vomiting, 3 of diarrhea-all of the latter effects were Grade 1 or 2 . One patient suffered from left foot dysesthesia and 1 from lower back and leg pains. One patient showed a very strange disease course with acute colitis associated with GuillainBarré syndrome; radiotherapy had to be interrupted after 18 of the 22 fractions planned and the patient was hospitalized for 3 months, 1 month of which was in intensive care.

\section{DISCUSSION}

Our series, collected in nine institutions of the Rare Cancer Network, is the largest of PSEL, with 52 patients treated over a 20-year period. The second largest, from the Mayo Clinic, was reported on 49 patients; however, the observation period spanned 62 years and predated the era of modern radiotherapy and chemotherapy (4).

\section{Patient characteristics, symptoms, and signs}

In our study, 46 of the 52 patients $(88 \%)$ were older than age 40 years, which is comparable to the $80-82 \%$ reported by others $(4,6)$. Although PSEL has been described in pediatric patients (14-16), this disease predominantly affects older people with a median age of 55 to 65 years (17-19). In our series, the median age was 61.5 years. The male preponderance with $69 \%$ is comparable to that of other authors (i.e., between 60-76\%) $(4,6,20)$.

In the present experience, the symptoms and signs were those to be expected with any epidural tumor located in the spinal canal, namely varying degrees of upper or lower limb weakness $(92 \%)$ and back $(79 \%)$ or neck pain $(11 \%)$. In 
addition, varying sensory deficits (69\%) and impairment of bladder $(23 \%)$ or bowel $(17 \%)$ functions were seen. This corresponds to the symptoms and signs reported by others: Salvati et al. reported $100 \%$ of back pain and $89 \%$ of motor impairment (2); Cappellani et al. reported $70 \%$ of back pain (20). Lymphoma is a disease which can be accompanied with "B" symptoms, such as weight loss, night sweats, and fever. However, patients who present with a clinical Stage I, as is the case in $92 \%$ of our patients, or Stage II ( $8 \%$ in our series) are usually free of systemic manifestations. In our study, only 2 patients presented with unexplained weight loss and 1 patient presented with night sweats. The area of involvement was mainly in the thoracic segment. Sixty-five percent of the cases in our study were localized in this portion of the spine. This finding is in agreement with those of other authors such as Di Marco et al. and Love et al., who observed it in $78 \%$ and $64 \%$ of their cases, respectively (21, 22). However in other studies, the area of involvement was almost equally distributed between the thoracic and the lumbar portions $(23,24)$. Epelbaum reported that none of their patients had a cervical spine involvement (6) and others revealed that cervical involvement was the least common $(2,23,25)$. In our series, $10 \%$ of the patients had a cervical lecation of the tumor mass, which was the third most commonly affected area.

\section{Diagnostic workup}

For all patients, a medical history was taken and physical examination was carried out. Ninety-eight percent of our patients underwent a spinal $\mathrm{CT}$ scan and $52 \%$ had an MRI. Even if MRI is the standard imaging procedure for spinal lesions and has now replaced myelography, still, 34 of our 52 patients diagnosed between 1982 and 2002 underwent a myelogram, but mainly in the earlier period. In 1986, Epelbaum et al. described myelography as "the most reliable procedure for the investigation and localization of cord tumors as it usually revealed a complete block to the flow contrast media" (6). In the series of Rathmell et al., the clinical diagnosis of extradural compression was confirmed by myelography for 20 of their 22 patients (19), whereas in the series of Cappellani et al., a myelography was performed for all patients (20). Most of our patients had a complete systemic workup for lymphoma: whole-body CT scan was done in $77 \%$ of cases, bone marrow assessment (aspiration or biopsy) in $96 \%$, cerebrospinal fluid examination in $50 \%$, lactic dehydrogenase measured in $84 \%$, and white blood cell count in $94 \%$.

\section{Treatment}

Surgery. In our study, 48 patients $(92 \%)$ underwent a decompressive laminectomy. Partial resection was performed in 22 cases (42\%) and complete resection in 7 cases $(13 \%)$. Traditionally, surgery is the first therapeutic approach in malignancies compressing the spinal cord. Because lymphomas are very chemo- and radiosensitive tumors, the indications for surgery have been reduced and limited to laminectomy or even biopsy only, leaving the major role to RT and chemotherapy $(6,17)$. However, especially because the tumor type is unknown at the time of initial presentation, decompression, and, in some instances, partial removal of the tumor mass may represent a good option. It immediately alleviates the spinal cord compression while establishing the correct histologic diagnosis.

Radiation therapy. All patients in our series underwent radiation therapy and for 20 of them, RT was given alone. The median RT dose was 36 Gy (range, 6-50 Gy). Radiation doses employed by various authors vary widely, with ranges between 20 and $60 \mathrm{~Gy}(4,24)$, and doses of at least $25 \mathrm{~Gy}$ are recommended $(18,23)$. It appears though from our multivariate analysis that a dose of at least $36 \mathrm{~Gy}$ at 2 Gy per fraction or its equivalent should be considered.

Our data suggest that a radiation volume more than focal seemed to influence the outcome. As many authors advise extending the field of irradiation to two or three vertebral segments both above and below the tumor site, and sometimes laterally to include the mediastinal and retroperitoneal lymph nodes, we would agree that in epidural lymphoma, the use of relatively large volumes seems to be appropriate.

Chemotherapy. Sixty-one percent of patients underwent chemotherapy; 14 received it after RT, 16 before RT, 1 had a "sandwich" modality treatment, and 1 a concomitant treatment. No patient received chemotherapy alone. Although Oviatt $e t$ al. reported on 2 patients with epidural compression secondary to NHL who were successfully treated by chemotherapy alone (26), most authors have opted for a treatment based on surgery followed by radiation therapy (2, $4,6,18,19,25)$.

Combined modality treatment. Our multicentric study suggests that combined modality treatment, including RT and chemotherapy, seems to be the most efficient treatment for primary spinal epidural lymphoma, with a local control of $88 \%$ and a 5-year overall survival of $69 \%$. Di Marco $e t$ al. observed 9 patients with PSEL and reported a long-term survival for 2 of them. Those 2 long-term survivors were those who received a complete chemotherapeutic course after RT (21). Epelbaum et al. with intensive therapy, using RT and combination chemotherapy, achieved an actuarial 5 -year survival rate of $66 \%$ (6). Rathmell et al. reported a significant difference between patients treated with radiation therapy alone and those with combined modality with an overall actuarial survival of $33 \%$ and $86 \%$, respectively (19). In our series, among the 20 patients who received RT alone, 11 suffered a systemic relapse, from which 7 died, 2 are still alive with disease 4 and 9 years after the end of the initial treatment, and 2 are alive without disease 4 and 15 years, respectively, after treatment. In addition, of those patients treated with RT alone, 1 had a local relapse and died 8 months after the end of the treatment. Among the 32 patients who received a combined modality treatment, 19 (59\%) are still alive without disease 2-13 years after the treatment, 8 had a systemic relapse, and 5 a local relapse. In multivariate analysis, combined modality treatment was superior to $\mathrm{RT}$ alone $(p=0.01)$.

Central nervous system prophylaxis. Mackintosh et al. 
(27) have made an analysis of CNS involvement in lymphoma, which showed a significantly increased risk of CNS relapse for patients with extradural disease. However, as the majority of the patients had disseminated lymphoma in their series, it is not certain whether patients with localized disease carry the same risk. In our series, CNS prophylaxis by intrathecal therapy with methotrexate was given in 10 patients $(19 \%)$, whereas another 4 received intrathecal chemotherapy in combination with systemic treatment for relapse. Of the latter, none had received prophylactic intrathecal chemotherapy during initial treatment.

\section{Neurologic outcome and general prognosis}

In our series, a complete neurologic response was observed in 12 of the 48 patients $(25 \%)$ who presented initially with motor weakness. Even if it can take several months to achieve a complete recovery, complete neurologic response was the most significant favorable prognostic factor in the multivariate analysis with regard to OS $(p=0.001)$. Eeles et $a l$. and Rathmell et al. in their series also found that the outcome depends on the neurologic status after treatment $(19,25)$.

\section{Overall prognosis}

With regard to the outcome of patients with PSEL, overall prognosis was relatively good: 25 patients are alive without disease $2-17$ years after the treatment, 3 are alive with disease after $4-9$ years, 6 died without disease $10-89$ months after treatment, and 18 died with disease 6-121 months after treatment. Similar findings have also been made by others $(4,6,22,23)$.

\section{Local control}

The local control rate in this series was $88 \%$; after therapy, 6 patients $(11 \%)$ progressed locally. In their series, Rathmell et al. found also an excellent local control of $88 \%$ at 10 years, with only 2 patients failing to achieve a permanent local control (19). Only 1 of their 12 patients treated with RT alone relapsed within the radiation field, 10 months after treatment (19), Another patient had a residual paraspinal mass on X-ray and developed clinical evidence of recurrent spinal cord compression, as well as generalized disease. A further 7 patients, all treated with RT alone, relapsed at distant sites, mainly in the CNS and lymph nodes, without local failure.

\section{Systemic relapse}

Twenty-two patients (42\%) suffered from a systemic relapse, mainly in the lymph nodes $(n=9)$, chest or abdomen $(n=5)$, bone marrow $(n=4)$, and CNS $(n=4)$. Of these, 14 died with disease, 1 died without disease, 3 are alive with disease, and 4 are alive and free of disease. Among the 10 patients of Epelbaum et al. (6) with spinal cord presentation of NHL, 7 achieved a complete remission after initial treatment. Four of them treated by combined modality treatment relapsed after a median time of 15 months, with relapses in the bone, the bone marrow, the CNS, and the mediastinum. The other 3 remained free of disease, whereas in the last 3 patients, the disease progressed while the patients were on initial treatment.

\section{Prognostic factors}

As was shown in other studies of the Rare Cancer Network, the larger collection of data in rare cancers enabled us to attempt to define pre-therapeutic and therapeutic prognostic factors. For example, in our study we determined that sex did not influence the prognosis, but that age did have an impact as univariate analyses with a significant survival and DFS advantage for patients aged less than 63 years $(p=$ 0.001 and 0.006 respectively). However, it should be noted that younger patients tended to be treated more aggressively both with radiation therapy and chemotherapy because, among the 27 patients who were younger than 63 years old, $19(70 \%)$ received a combined modality treatment versus 13 (52\%) of 25 patients older than 63 years.

Concerning the treatment, we found that a radiotherapy volume more than focal, and the total radiotherapy dose (>36 Gy) and combined modality therapy influenced overall survival ( $p=0.001,0.01$, and 0.005 , respectively), by multivariate analysis. Regarding the tumor grade, patients with high or intermediate grade NHL were not treated differently since $68 \%$ and $83 \%$ of patients with respectively, intermediate- and high-grade PSEL, received a combined modality treatment. However, only $25 \%$ of patients with low-grade NHL received combined modality treatment. Altogether however, grade did not seem to influence the prognosis.

\section{CONCLUSION}

Spinal epidural lymphoma is obviously a very rare entity and for this reason we should be very cautious in drawing too firm conclusions, especially with regard to therapy. However, because we have analyzed one of the largest groups of patients with PSEL, we would like to propose some diagnostic and therapeutic standards, based on our data.

1. Diagnostic workup should include in the acute phase an MRI (or if not available, a CT scan) of the entire spine and tissue sampling during the emergency surgery for a definitive pathologic diagnosis. Elective workup should consist of a complete medical history and physical examination, full blood counts, blood chemistry including serum electrophoresis, CSF examination, whole-body CT scan or MRI, and bone marrow biopsy or aspiration. Although no patient in our series underwent a positron emission tomography or positron emission tomography-CT scan, this examination should probably be part of the workup in the future.

2. Treatment will almost always include in the acute phase some form of emergency decompressive surgery, with or without resection, followed by RT and chemotherapy. RT plays a central role and should be given to a volume encompassing the epidural mass, with two to three vertebral bodies above and below the lesion at a dose 
of at least 36 Gy at 2 Gy per fraction or its equivalent. Chemotherapy should almost always be added to RT, using four to six cycles of cyclophosphamide, doxoru- bicin, vincristine, and prednisone or cyclophosphamide, doxorubicin, vincristine, and prednisone-like regimes, especially in high- or intermediate-grade PSEL.

\section{REFERENCES}

1. Boukobza M. Mazel C, Touboul E. Primary vertebral and spinal epidural non-Hodgkin's lymphoma with spinal cord compression. Neuroradiology 1996;38:333-337.

2. Salvati M, Cervoni L, Artico M, et al. Primary spinal epidural non-Hodgkin's lymphomas: A clinical study. Surg Neurol $1996 ; 46: 339-344$.

3. Lim CCT, Chong BK. Spinal epidural non-Hodgkin's lymphoma: Case reports of three patients presenting with spinal cord compression. Singapore Med J 1996;37:497-500.

4. Haddad P, Thaell JF, Kiely JM, et al. Lymphoma of the spinal extradural space. Cancer 1976;38:1862-1866.

5. Levitt LJ, Dawson CM, Rosenthal DS, et al. CNS involvement in the non-Hodgkin's lymphomas. Cancer 1980;45:545-552.

6. Epelbaum R, Haim N, Ben-Shahar M, et al. Non-Hodgkin's lymphoma presenting with spinal epidural involvement. Cancer 1986;58:2120-2124.

7. Goffinet DR, Warnke R, Dunnick NR, et al. Clinical and surgical (laparotomy) evaluation of patients with non-Hodgkin's lymphomas. Cancer Treat Rep 1977;61:981-992.

8. Rudders RA, Ross ME, DeLellis RA. Primary extranodal lymphoma. Cancer 1978;42:406-416.

9. Carbone PP, Kaplan HS, Mushoff K, et al. Report of the committee on Hodgkin's disease staging classification. Cancer Res 1971;31:1860-1861.

10. The Non-Hodgkin's lymphoma pathologic classification project. National Cancer Institute sponsored study of classifications of non-Hodgkin's lymphomas. Summary and description of Working Formulation for clinical usage. Cancer 1982;49: 2112-2135.

11. Kaplan ES, Meier P. Non-parametric estimation from incomplete observations. J Am Stat Assoc 1958;53:457-481.

12. Peto R, Pick MC, Armitage P, et al. Design and analysis of randomized clinical trials requiring prolonged observations of each patients. I. Introduction and design. $\mathrm{Br} J$ Cancer 1976; 34:585-612.

13. Cox DR. Regression models and life tables. J Roy Stat Soc 1972:34:187-220.

14. Schwechheimer K, Hashemian A, Ott G, et al. Primary spinal epidural manifestation of malignant lymphoma. Histopathology $1996 ; 29: 265-269$.
15. Mora J, Wollner N. Primary epidural non-Hodgkin's lymphoma: Spinal cord compression syndrome as the initial form of presentation in childhood non-Hodgkin's lymphoma. Med Pediatr Oncol 1999;32:102-105.

16. Raco A, Cervoni L, Salvati M, et al. Primary spinal epidural non-Hodgkin's lymphomas in childhood: A review of 6 cases. Acta Neurochir 1997;139:526-528.

17. Grant JW, Kaech D, Jones DB. Spinal cord compression at first presentation of lymphoma-A review of 15 cases. Histopathology 1986;10:1191-1202.

18. Lyons MK, O'Neill BP, Marsh WR, et al. Primary spinal epidural non-Hodgkin's lymphoma: Report of 8 patients and review of the literature. Neurosurgery 1992;30:675-679.

19. Rathmell AJ, Gospodarowicz MK, Sutcliffe SB, et al. Localized extradural lymphoma: Survival, relapse pattern and functional outcome. Radiother Oncol 1992;24:14-20.

20. Cappellani G, Giuffrè F, Tropea R, et al. Primary spinal epidural lymphomas. J Neurosurg Sci 1986;30:147-15I.

21. Di Marco A, Campostrini F, Garusi GF. Non-Hodgkin's lymphoma presenting with spinal epidural involvement. Acta Oncol 1989;28:485-488.

22. Love GJ, Miller RH, Kernohan JW. Lymphomas of spinal epidural space. Arch Surg 1954;69:66-76.

23. Friedman M, Kim TH, Panahon AM. Spinal cord compression in malignant lymphoma: Treatment and results. Cancer 1976; 37:1485-1491.

24. Vasudev Rao T, Narayanaywamy KS, Shankar SK, et al. Primary spinal epidural lymphomas: A clinico-pathological study. Acta Neurochir 1982;62:307-317.

25. Eeles RA, O'Brien $P$, Horwich A, et al. Non-Hodgkin's lymphoma presenting with extradural spinal cord compression: Functional outcome and survival. Br.J Cancer 1991;63:126129.

26. Oviatt DL, Kirshner HS, Stein RS. Successful chemotherapeutic treatment of epidural compression in non-Hodgkin's lymphoma. Cancer 1982;49:2446-2448.

27. Mackintosh FR, Colby TV, Podolsky WJ, et al. Central nervous system involvement in non-Hodgkin's lymphona: An analysis of 105 cases. Cancer 1982;49:586-595.

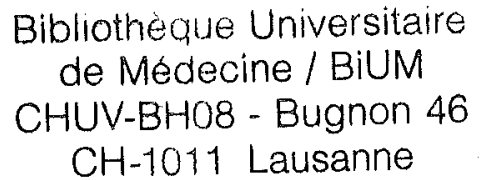

Bibliothèque Universitaire CHUV-BHO8 - Bugnon 46 $\mathrm{CH}-1011$ Lausanne 